\title{
Microscopic analysis of the stainless steel weld metal after long-term thermal exposition in the primary circuit of the nuclear power plant
}

\author{
D. Grgač, L. Caaplovič, M. Dománková, P. Grgač* \\ Slovak University of Technology in Bratislava, Faculty of Materials Science and Technology in Trnava, \\ Paulínska 16, 91724 Trnava, Slovak Republic
}

Received 23 November 2016, received in revised form 28 March 2017, accepted 28 March 2017

\begin{abstract}
In the paper, results of microscopic analyses of the weld metal taken from weld joint of the thick-walled austenitic stainless steel pipeline of the primary circuit of the nuclear power plant WWER-440 are presented. The weld joint has been exposed in the main circulation pipeline approximately $180,000 \mathrm{~h}$ at temperatures approaching $300^{\circ} \mathrm{C}$. A sample taken from a top part of the multi-pass weld joint has been analyzed by scanning electron microscopy, energy dispersive X-ray analysis, transmission electron microscopy and high-resolution transmission electron microscopy. The analyzed weld metal exhibited a duplex microstructure consisting of the austenite phase and a semi-continual network of $\delta$-ferrite phase. The mean hardness of the weld metal was $195 \mathrm{HV} 1$. In the weld metal, globular non-metallic inclusions, as well as carbonitride particles of the MX type and chromium based carbide particles of $\mathrm{M}_{23} \mathrm{C}_{6}$ type, were identified. At the phase interfaces of $\delta$-ferrite/austenite, the presence of particles of $\sigma$ phase placed in the volumes of $\delta$-ferrite network was detected. The presence of $\sigma$-phase and $\mathrm{M}_{23} \mathrm{C}_{6}$ carbide particles in the top part of the weld can be explained as a consequence of the short-term expositions of the weld metal in the temperature range from about 900 to $600{ }^{\circ} \mathrm{C}$ during the multi-pass welding process of the primary circuit of the nuclear power plant. High-resolution transmission electron microscopy analysis of the ferrite phase regions revealed in thin foils the presence of mottled contrast indicating the spinodal decomposition of the $\delta$-ferrite to Cr-rich $\alpha^{\prime}$ - and Fe-rich $\alpha$-phases. It is supposed that the decomposition of the $\delta$-ferrite phase started during final stages of the multi-pass welding process at thermal expositions around $475^{\circ} \mathrm{C}$ and continued during long-term exposition at the operation temperatures of the primary circuit.
\end{abstract}

K e y words: stainless steel, weld metal, low-temperature thermal aging, $\sigma$-phase, carbide phase, $\alpha^{\prime}$-phase

\section{Introduction}

Austenitic and duplex stainless steels are used in nuclear power plants (NPP) for primary recirculation piping operating at temperatures around $300^{\circ} \mathrm{C}$. Welded joints of the pipes are considered to be critical load-bearing components. From this point of view, it is important to know and predict their structural state and mechanical properties during long-term service. The weld metals of the high alloyed corrosion resistant steels used in NPP usually exhibit a duplex microstructure consisting of the austenite phase and $\delta$-ferrite phase [1]. Some amount of the $\delta$-ferrite is required in the weld metal to avoid hot cracking during welding $[2,3]$. In fully austenitic weld metal, hot cracking may take place due to segregation of impurity elements such as phosphorus and sulphur to the remaining liquid phase resulting in the formation of low melting eutectics.

Stainless steels containing $\delta$-ferrite are sensitive to thermal aging processes. The main consequence of thermal aging in the temperature range of approx-

*Corresponding author: e-mail address: peter.grgac@stuba.sk 
imately 300 and $500{ }^{\circ} \mathrm{C}$ is the embrittlement of the steel. The phenomenon of low-temperature thermal aging and its influence on microstructure and material properties has been studied in various types of stainless steels [4-49]. The primary consequence of the low-temperature thermal aging of ferritic and ferrite containing stainless steels has been associated with the spinodal decomposition of ferritic solid solution into Fe-rich $\alpha$ - and Cr-rich $\alpha^{\prime}$-phases. This phase separation ferrite $\rightarrow\left(\alpha+\alpha^{\prime}\right)$ is related to a miscibility gap in the phase diagram of the binary Fe-Cr system. The lattices of both, Fe-rich $\alpha$ and Cr-rich $\alpha^{\prime}$-phases, are body-centered cubic and both phases are of extremely fine scales. The resulting structure of the spinodal decomposition is three-dimensional interconnected $\alpha+$ $\alpha^{\prime}$ network developed on a nanometer scale [12].

The decomposition of ferrite phase results in a phenomenon which is also known as " $475^{\circ} \mathrm{C}$ embrittlement" because the rate of embrittlement of the ferrite is usually highest at this temperature. However, the decomposition of the $\delta$-ferrite phase may occur as well as at temperatures lower than $475^{\circ} \mathrm{C}$ during long-term expositions. The embrittlement behavior that has been observed in stainless steels led the researchers to the investigation of the influence of low-temperature thermal aging on stainless steels weld joints [50-60]. The results of the experimental investigations have shown that the low-temperature decomposition of the ferrite $\rightarrow\left(\alpha+\alpha^{\prime}\right)$ reduces both corrosion resistance and mechanical properties of the corrosion resistant steels and their welds and weld metals. The low-temperature decomposition of ferrite phase leads to an increased hardness and strength but decreases impact toughness and ductility.

It is well established that the corrosion resistant steels undergo various microstructural changes also during the high-temperature expositions depending on the temperature, chemical composition of the steel and exposure time. Precipitation processes occurring in these steels in the high-temperature range above $550^{\circ} \mathrm{C}$ result in the development of various intermetallic phases, carbides and nitrides. Therefore, considerable attention has been paid to the precipitation of secondary phases in the corrosion resistant steels with ferrite/austenite duplex microstructure in the conditions of high-temperature isothermal aging [61-72]. Less information is available concerning the formation of secondary phases during the welding and continuous cooling after high-temperature treatment [73-79].

A detailed knowledge of the microstructure and nanostructure of the weld metal after long-term thermal exposition in the primary circuit of the NPP is of great interest as the structure and properties of the weld may change during welding and long-term service at operation temperatures. Effects of long-term operation and additional thermal and thermo-strain aging on the microstructure and mechanical properties of
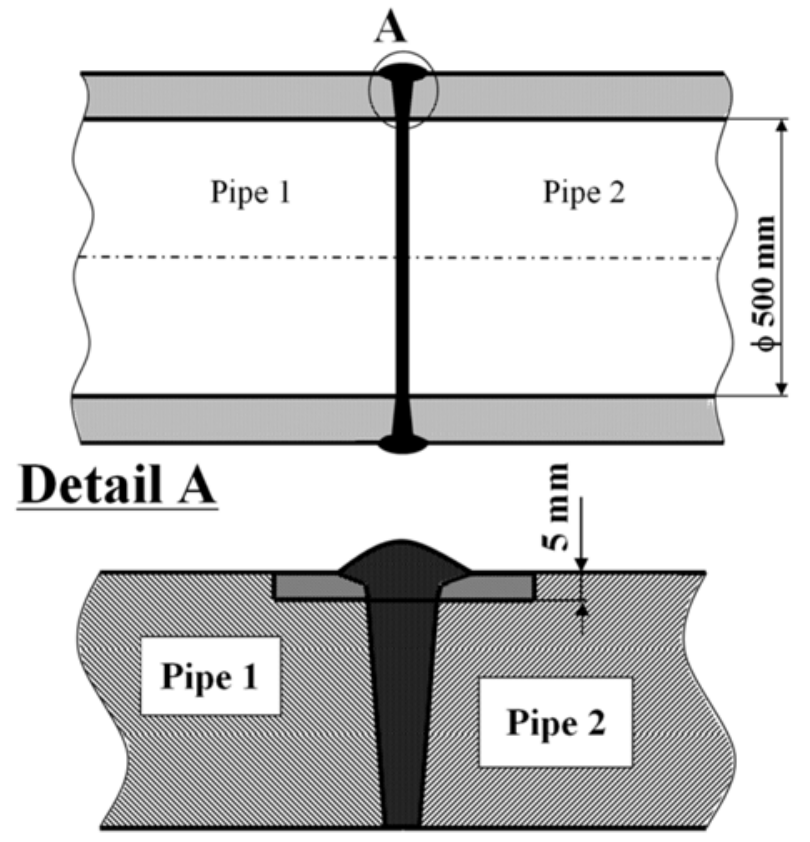

Fig. 1. Schemes of a weld joint in the primary piping and a $5 \mathrm{~mm}$ thick sample (in the Detail A) taken from the top part of the welded joint.

NPP WWER-440 pipeline welded joints with austenite/ferrite duplex microstructure of the weld metal were analyzed by Mamaeva et al. [53]. The authors state that after $100,000 \mathrm{~h}$ of operation in the primary circuit and additional aging at $450{ }^{\circ} \mathrm{C} / 1500 \mathrm{~h} \delta$-ferrite phase of the weld metal decomposed in $\alpha$-phase and chromium rich $\alpha^{\prime}$-phase. The authors did not show the microstructure of the weld metal in the nano-scaled range after long-term exposition at the operation temperature of the NPP.

In the present work, a sample taken from the top part of the multi-pass weld joint long-term thermally aged in NPP with the reactor of the WWER-440 type has been microscopically analyzed. This paper is aimed at the microstructure characterization of the weld metal service-exposed in the main coolant pipeline at the temperatures approaching $300^{\circ} \mathrm{C}$ during approximately 180,000 h.

\section{Experimental}

The long-term service-exposed material was obtained from the main coolant pipeline of the WWER-440 NPP [80]. The sample for microscopic investigation was the part of welded joint taken from the austenitic corrosion-resistant steel pipeline with the inside diameter of $500 \mathrm{~mm}$. The specimen was mechanically cut out from the top of the welded joint. The analyzed region of the weld metal was located approximately $5 \mathrm{~mm}$ under the surface of the pipe - Fig. 1 . 
Table 1. Mean chemical composition of the analyzed weld metal measured on SEM by EDX (wt.\%)

\begin{tabular}{ccccccc}
\hline $\mathrm{Si}$ & $\mathrm{Mn}$ & $\mathrm{Cr}$ & $\mathrm{Ni}$ & $\mathrm{Mo}$ & $\mathrm{V}$ & $\mathrm{Fe}$ \\
\hline 0.35 & 2.5 & 19.0 & 11.3 & 2.7 & 0.7 & Bal. \\
\hline
\end{tabular}

The mean chemical composition of the weld metal analyzed in this work is given in Table 1.

Microstructural observation of ground, polished and etched sample of the weld metal was carried out using the JEOL JSM 7600F scanning electron microscope (SEM) equipped with an energy-dispersive $\mathrm{X}$-ray (EDX) spectrometer. For the individual secondary phase identification, transmission electron microscopy (TEM) of extraction carbon replicas and thin foils of the weld metal was utilized. The replicas were obtained from mechanically polished and etched surfaces of the sample. The replicas were stripped from the specimen in the solution of $\mathrm{CH}_{3} \mathrm{COOH}: \mathrm{HClO}_{4}=$ $4: 1$ at $20^{\circ} \mathrm{C}$ and $20 \mathrm{~V}$. Small discs of $3 \mathrm{~mm}$ in diameter and the thickness about $0.1 \mathrm{~mm}$ taken from the weld metal were jet-electropolished in electrolyte $\mathrm{HNO}_{3}: \mathrm{CH}_{3} \mathrm{OH}=3: 7$, at $0^{\circ} \mathrm{C}$ and $15 \mathrm{~V}$ to obtain transparent areas near the central hole. The electropolishing was done by a Struers TENUPOL 5 twin-jet unit. TEM observations were performed using JEOL $200 \mathrm{CX}$ operating at $200 \mathrm{kV}$. High-resolution TEM (HRTEM) observations were realized by the microscopes of Philips CM 300 and Titan 80-300 operating at $300 \mathrm{kV}$, equipped with an EDX spectrometers. Before the observations in HRTEM, the thin foils were plasma cleaned using the equipment SPI Supplies Plasma Prep ${ }^{\mathrm{TM}}$ Plasma Cleaner for $20 \mathrm{~min}$. For the plasma generation, the mixture of gases $(75 \%$ argon and $25 \%$ oxygen) was used.

The hardness of weld metal was measured at room temperature using hardness tester Buehler Indentamet 1105 . The sample for hardness measurement was prepared by grinding and mechanical polishing. The mean hardness of the weld metal, determined by averaging values for more than 30 indents, was 195 HV 1. Dimensions of the analyzed sample were relatively small, and therefore it was not possible to analyze other mechanical properties of the weld metal.

\section{Results}

Figure 2 shows photographs of the polished and etched sample from the top part of the welded joint. On the ground top of the weld, so-called annealing welds [80] made by four runs of the welding electrodes are visible - Fig. 2a. The macrostructure of the analyzed weld metal is documented in Fig. 2b. In this part of the welded joint, the width of the weld metal was approximately $18 \mathrm{~mm}$. Figure 3 documents the microstructure in the middle part of the analyzed

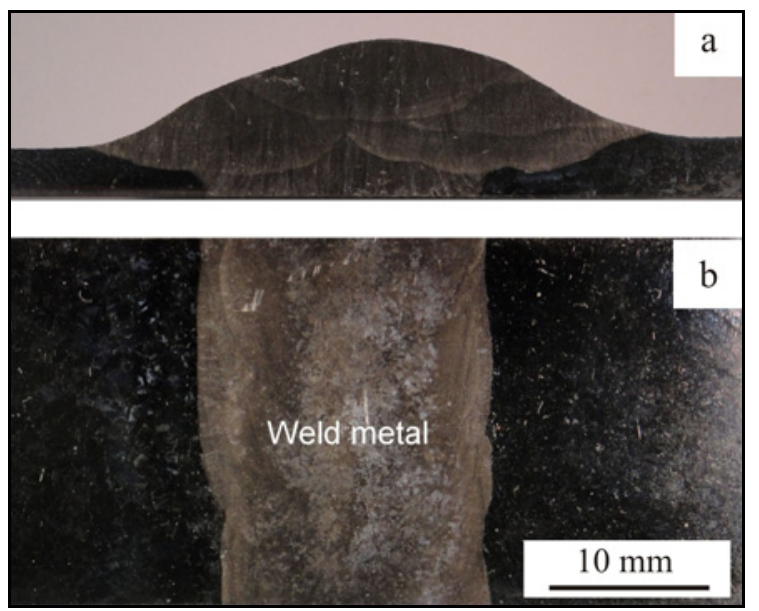

Fig. 2. Photographs of the analyzed welded joint sample: a) view perpendicularly on the axis of the pipe direction. The surface of the weld was ground; b) bottom view - analyzed weld metal (ground, polished and etched sample).

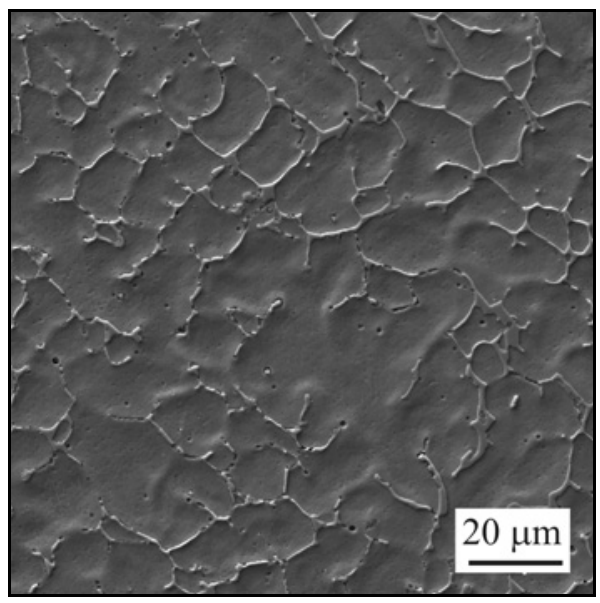

Fig. 3. Duplex weld metal microstructure showing morphological features of the austenite phase and semicontinuous network of the $\delta$-ferrite phase (SEM).

weld metal. As it can be seen, the weld metal exhibits mixed cellular/dendritic microstructure of the austenite phase with a semi-continuous network of $\delta$-ferrite phase located at the austenite phase boundaries.

To evaluate chemical composition of the matrix phases in the weld metal, EDX analysis was used. Table 2 provides the mean chemical composition of the austenite and $\delta$-ferrite phase identified in the weld metal. Each phase was analyzed on the etched sample using SEM at various places ten times. It was 
Table 2. Mean chemical composition of the matrix phases in the weld metal measured on SEM by EDX (wt.\%)

\begin{tabular}{lcccrrrr}
\hline & $\mathrm{Si}$ & $\mathrm{Mn}$ & $\mathrm{Cr}$ & $\mathrm{Ni}$ & $\mathrm{Mo}$ & $\mathrm{V}$ & $\mathrm{Fe}$ \\
\hline Austenite & 0.3 & 2.5 & 18.2 & 12.4 & 2.5 & 0.6 & Bal. \\
Ferrite & 0.4 & 2.0 & 24.3 & 5.8 & 5.0 & 0.9 & Bal. \\
\hline
\end{tabular}

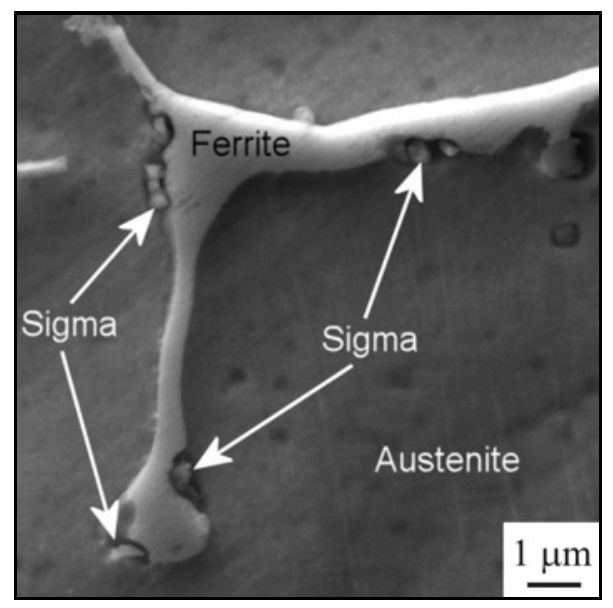

Fig. 4. The microstructure of the weld metal shoving secondary particles of the $\sigma$-phase on the interfaces $\delta$-ferrite/austenite (SEM).

found that the higher content of the ferrite stabilizing elements $\mathrm{Cr}, \mathrm{Mo}, \mathrm{Si}$ and $\mathrm{V}$ is localized in the $\delta$-ferrite, the austenite stabilizing elements $\mathrm{Ni}$ and $\mathrm{Mn}$ are placed predominantly in the austenite. As it follows from this analysis, $\delta$-ferrite phase has two times higher content of the molybdenum than the austenite phase, austenite has approximately two times higher nickel content than $\delta$-ferrite. The element partitioning between $\delta$-ferrite and austenite is consistent with the stabilizing effect of each element on the respective phase. The differences in the content of $\mathrm{Mn}, \mathrm{Si}$ and $\mathrm{V}$ in the $\delta$-ferrite and austenite are relatively small. These chemical compositions of matrix phases, austenite and $\delta$-ferrite, and the differences between them are in agreement with results presented by Chandra et al. [57] after the analysis of the stainless steel 316L weld metal.

Figure 4 documents small particles of the secondary phases observed at the austenite $/ \delta$-ferrite interfaces. Individual particles of these secondary phases, which will be later identified as $\sigma$-phase, were precipitated at the $\delta$-ferrite/austenite interfaces and penetrated into the $\delta$-ferrite phase. In Fig. 5a, individual particles of the $\sigma$-phase are documented in detail on thin foil using TEM. An electron diffraction pattern of the $\sigma$-phase particle is presented in Fig. 5b. The maximum size of the particles of the $\sigma$-phase detected in the weld metal was lower than $1 \mu \mathrm{m}$. In addition to the precipitates of $\sigma$-phase, particles of $\mathrm{M}_{23} \mathrm{C}_{6}$ carbides were identified in the analyzed weld metal. Fig-

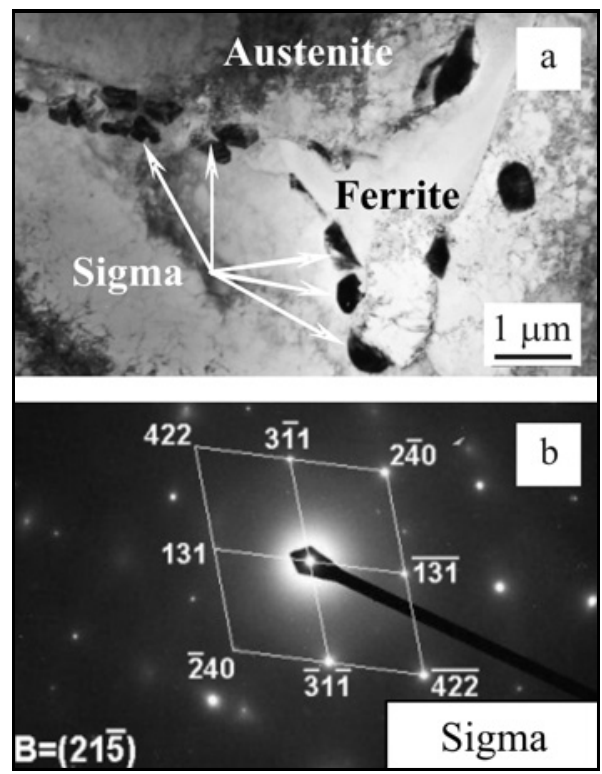

Fig. 5. Particles of $\sigma$-phase identified in the weld metal on the interface $\delta$-ferrite-austenite (a) and the corresponding electron diffraction pattern of the $\sigma$-phase (b).

(TEM/SAED, thin foil).

ure 6a from TEM documents the particles of these two secondary phases separated in the carbon replica. In Fig. 6b, the diffraction pattern taken from the carbide $\mathrm{M}_{23} \mathrm{C}_{6}$ is shown. Figure $6 \mathrm{c}$ documents the diffraction pattern of the $\sigma$-phase particle. SEM and TEM analyses of the weld metal also revealed that non-metallic inclusions and small carbonitride MX particles are present in the microstructure. These particles are located mainly in the austenite phase. As an example of these particles from welding process, spherical nonmetallic inclusions and angular MX particles located in the austenite phase interior can be seen in Fig. 7 on thin foil. Mean chemical compositions of the $\sigma$-phase and carbide particles identified in the analyzed weld metal are presented in Table 3 .

The phases formed in binary $\mathrm{Fe}-\mathrm{Cr}$ steels and ferrite containing corrosion resistant steels during low-temperature aging are in nanometer scale range. Hence, further investigation of the weld metal was conducted on thin foils by HRTEM. Figure 8a documents micrograph showing at relatively low magnification the precipitate-free $\delta$-ferrite region in the austenite matrix as well as a precipitate-free interface $\delta$-ferrite/austenite. The nanostructure of this $\delta$-ferrite phase is shown in Fig. 8b. This figure documents on 
Table 3. Mean chemical composition of the secondary phases in the weld metal, measured in carbon extraction replicas by $\operatorname{EDX}($ wt.\%)

\begin{tabular}{lccccrrrr}
\hline & $\mathrm{Si}$ & $\mathrm{Mn}$ & $\mathrm{Cr}$ & $\mathrm{Ni}$ & $\mathrm{Mo}$ & $\mathrm{V}$ & $\mathrm{Fe}$ \\
\hline$\sigma$ & 4.1 & 5.4 & 33.5 & 6.8 & 6.2 & 0.8 & Bal. \\
$\mathrm{M}_{23} \mathrm{C}_{6}$ & 0.6 & 4.1 & 52.8 & 1.7 & 18.2 & 3.4 & Bal. \\
$\mathrm{MX}$ & 1.1 & 1.3 & 43.5 & 1.5 & 38.4 & 12.2 & Bal. \\
\hline
\end{tabular}

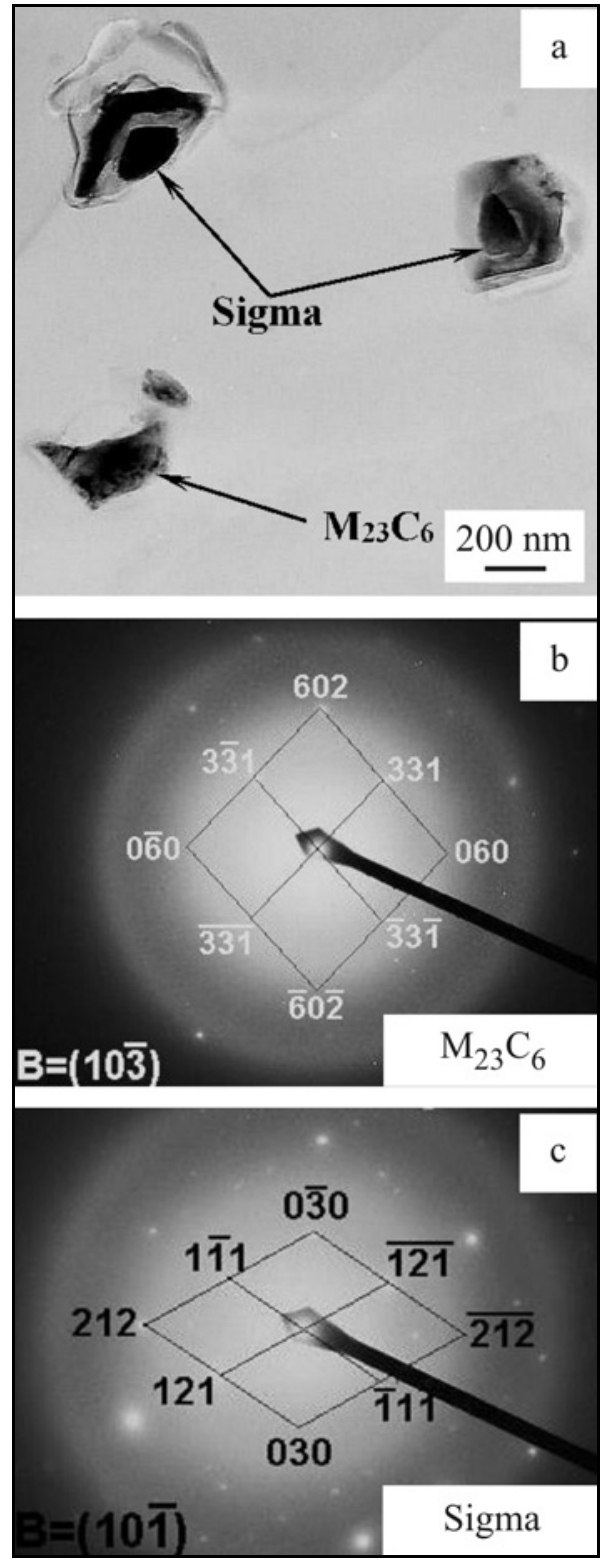

Fig. 6. Particles of the carbide $\mathrm{M}_{23} \mathrm{C}_{6}$ and $\sigma$-phase separated from the weld metal (a), the diffraction pattern of the carbide $\mathrm{M}_{23} \mathrm{C}_{6}(\mathrm{~b})$, the diffraction pattern of the $\sigma$-phase (c). (TEM, SAED, carbon extraction replica).

thin foil at high magnification the mottled appearance in the $\delta$-ferrite phase. Mottled contrast observed in thin foils on TEM is typical for the presence of

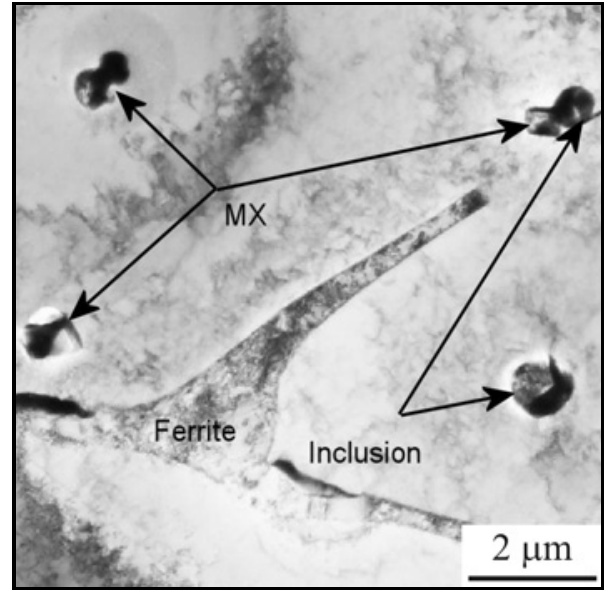

Fig. 7. Spherical inclusions and carbonitride MX particles in the microstructure of the weld metal. (TEM, thin foil).

spinodal decomposition of the ferrite phase to $\alpha+$ $\alpha^{\prime}$-phase. However, the contrast mechanism for this modulated structure is not clear, although it has been presumed to be due to differential oxidation of the two phases during the preparation of the TEM thin foils [27].

Field-emission gun TEM has been used to investigate the detailed nano-scaled structure of the ferrite phase in the analyzed weld metal. The HRTEM nano-scaled micrographs of the ferrite phase and corresponding electron diffraction pattern are shown in Fig. 9. The presence of small "light" and "dark" regions with sizes of about 2-4 nm can be seen in Fig. 9a. Detailed micrograph in Fig. $9 \mathrm{~b}$ also indicates that there is a coherent interface between the "light" and "dark" phases. An electron diffraction pattern documented on Fig. 9c corresponds to a bcc crystalline structure. The electron spots are overlapped due to the same crystalline structure in the analyzed region and similar lattice parameters of the attended phases.

These specific morphological features of the lowtemperature decomposition $\delta$-ferrite $\rightarrow \alpha+\alpha^{\prime}$ were observed on thin foils using HRTEM only in the ferrite regions and any such feature has not been noticed in the austenitic phase. This austenite phase free of mottled contrast is in agreement with the results of another TEM observations on thin foils after lowtemperature aging of ferrite/austenite (duplex) corrosion resistant steels $[5,27,51,58]$. 

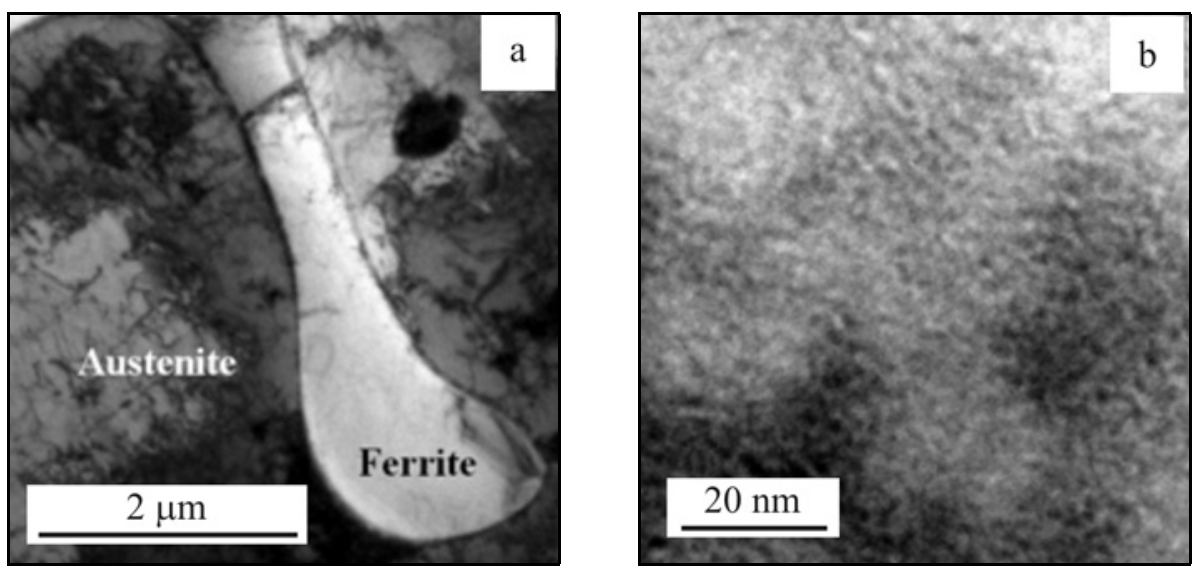

Fig. 8. $\delta$-ferrite/austenite microstructure of the weld metal (a) and modulated contrast observed in the ferritic phase of the weld metal (b). (HRTEM Philips CM 300, thin foil).
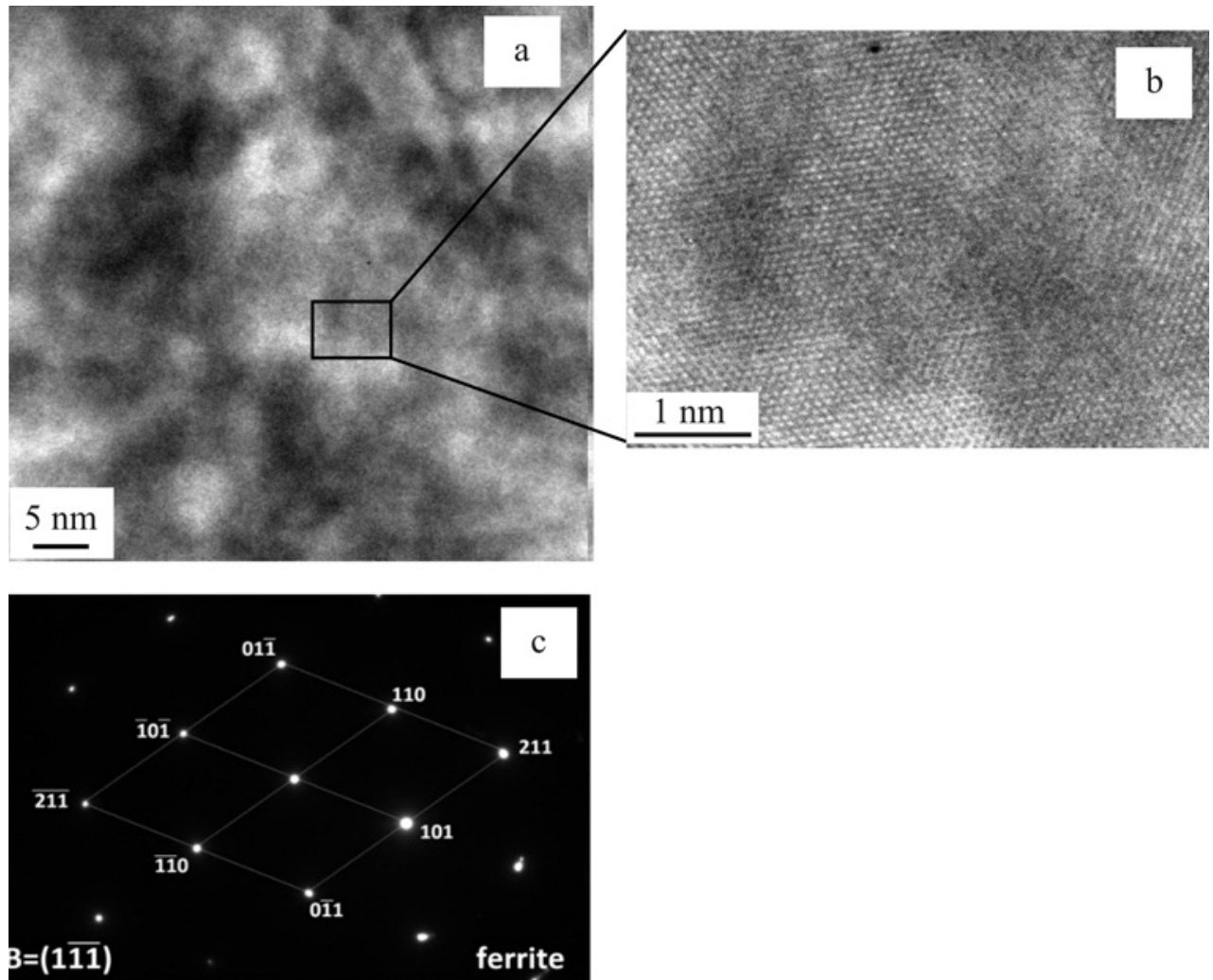

Fig. 9. The nanostructure of the decomposed ferrite phase at various enlargements (a,b) and diffraction pattern of the decomposed ferrite (c). (HRTEM Titan 80-300, thin foil).

\section{Discussion}

An interpretation of the reasons of microscopically observed structural features in the analyzed weld metal with two-phase austenite/ferrite matrix should be made very carefully because the thermal history of the weld joint formation is not known. As it follows from the SEM, TEM and HRTEM observations and analyses of the weld metal, two important and significant structural features were identified. The first one is the presence of particles of $\sigma$-phase and $\mathrm{M}_{23} \mathrm{C}_{6}$ carbides in the austenite $/ \delta$-ferrite weld metal. The second one is the nanometer-scaled mottled contrast (Fig. 8b) and nano-scaled heterogeneity (Fig. 9a) in the $\delta$-ferrite phase observed on thin foils using two types of HRTEM.

As it can be seen from Figs. 1 and 2, the analyzed part of the weld metal was located in the top part of the multi-pass welded joint. In the case of the multi-pass welding, each subsequent weld cycle 


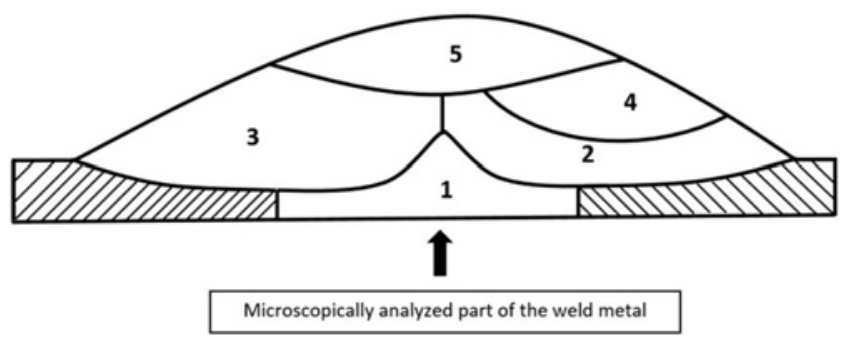

Fig. 10. Scheme of the top part of the weld joint - weld beads gradually formed in areas 1, 2, 3, 4 and 5. Microscopically analyzed part of the weld metal is marked by an arrow.

thermally affects a part of previous weld metal. The only hypothetical definition of the time-temperature conditions for documented structural features in the weld metal is possible as the thermal conditions by the weld joint formation are unknown. We only know that over the analyzed volume of the weld metal, further 4 weld beads were created, as it is presented in a photograph of the weld joint in Fig. 2a and schematically showed by the sketch of the weld in Fig. 10. Microscopically analyzed zone of the weld metal is in Fig. 10 marked with an arrow and number 1; next weld beads are marked by numbers from 2 to 5 . As it is clear from the macrostructure of weld in Fig. 2a and the scheme of weld in Fig. 10, macroscopically distinguishable volumes of the weld metal were developed in the sequence from 1 to 5 . It means that the analyzed zone of weld metal marked by an arrow in Fig. 10 was four times thermally affected by the formation of upper weld beads.

The presence of the intermetallic $\sigma$-phase particles and $\mathrm{M}_{23} \mathrm{C}_{6}$ carbides in the analyzed part of the weld metal indicates that these secondary particles were created during high temperature expositions of the weld bead No.1 in the process of the multi-pass welding. $\sigma$-phase in the corrosion resistant steels is an intermetallic phase on the ferrous base with relatively high content $\mathrm{Cr}$, containing other alloying elements, present in the steel $[66,73,76]$. This intermetallic phase is usually formed in the temperature range between 600 and $950^{\circ} \mathrm{C}$. It is well known that in the duplex corrosion resistant steels the $\sigma$-phase preferentially nucleates at the ferrite/austenite interfaces $[66,68]$ and grows towards the ferrite. In the isothermal conditions the $\sigma$-phase has $C$-curve formation kinetics [67] with a minimum incubation time of several minutes at the temperatures from 850 to $900^{\circ} \mathrm{C}[61,70] . \sigma$-phase formation takes place by consumption of chromium and other alloying elements present in the $\delta$-ferrite with very little or no contribution of these elements from adjacent austenite.

Precipitation of the $\mathrm{M}_{23} \mathrm{C}_{6}$ carbides in the corrosion resistant steels generally occurs at temperatures higher than $550^{\circ} \mathrm{C}$. Its formation has been widely observed upon isothermal expositions above this temperature. The kinetics of the $\mathrm{M}_{23} \mathrm{C}_{6}$ carbide formation depends mainly on the chemical composition of the steel and the thermal conditions of expositions (isothermal exposition during service or continuous cooling from high temperatures after solution annealing, forming or welding). For purposes of the explanation of the occurrence of $\mathrm{M}_{23} \mathrm{C}_{6}$ carbide particles identified in the analyzed weld metal, data about formation kinetics of this carbide phase are necessary. Kwang Min Lee et al. [62] observed particles of the $\mathrm{M}_{23} \mathrm{C}_{6}$ carbides in the SAF 2205 duplex stainless steel after short-term annealing for $15 \mathrm{~min}$ at the temperature of $800{ }^{\circ} \mathrm{C}$. Recently, the initial stage and growth mechanism of $\mathrm{M}_{23} \mathrm{C}_{6}$ carbides in the solution treated austenitic stainless steel 304L have been investigated using in situ annealing experiment [81]. In situ observations were carried out by TEM with a specially designed heating holder. First $\mathrm{M}_{23} \mathrm{C}_{6}$ carbide particle was observed after 1-minute exposition at the temperature $650^{\circ} \mathrm{C}$.

From presented results concerning the thermal conditions and kinetics of formation of the $\sigma$-phase particles and $\mathrm{M}_{23} \mathrm{C}_{6}$ carbides in corrosion resistant steels, it can be supposed that these two secondary phases identified in the analyzed part of the weld metal were developed during multi-pass welding at substantially higher temperatures (between about 900 and $600^{\circ} \mathrm{C}$ ) than are the operation temperatures in the primary piping of the NPP WWER-440.

However, the question arises, how it is possible that in the same volume of weld metal, in which occurs high-temperature secondary $\sigma$-phase and $\mathrm{M}_{23} \mathrm{C}_{6}$ carbides, the morphological features of low-temperature decomposition of $\delta$-ferrite are found, as mottled contrast and nano-heterogeneity, as presented in Figs. 8b and $9 \mathrm{a}$, respectively. A simple explanation would consist of finding that nano-heterogeneity in ferritic phase of the weld metal was created during long-term operation of a nuclear power plant at temperatures around $300^{\circ} \mathrm{C}$. The following analysis suggests that nano-heterogeneity observed in the net of $\delta$-ferrite phase in the weld metal is likely began to form at the end of the welding process of nuclear power plant primary circuit piping segments.

It is generally accepted that the thermal exposition of ferritic and ferrite containing stainless steels over $300^{\circ} \mathrm{C}$ and below roughly about $500^{\circ} \mathrm{C}$ may cause decomposition of the ferritic phase to Cr-rich $\alpha^{\prime}+$ Fe-rich $\alpha$-phase. Considering the HRTEM observations of another studies on thin foils [5, 27, 30, 35] and our results it can be assumed that mottled image (Fig. 8b) and heterogeneity of the nanometric range observed in the $\delta$-ferrite regions of the analyzed weld metal (Fig. 9a) are associated with the redistribution of chromium and other alloying elements due to 
low-temperature decomposition of the ferrite phase to $\alpha+\alpha^{\prime}$ phase.

There are several results from isothermal experiments, indirectly indicating the kinetic of the ferrite decomposition in a critical temperature range near $475^{\circ} \mathrm{C}$ where the decomposition of ferrite phase to the $\alpha+\alpha^{\prime}$-phases runs most rapidly. Shariq et al. [59] using atom probe field ion microscopy have shown that phase separation in the ferrite phase of super duplex stainless steels weld metal was significant already after $1 \mathrm{~h}$ of aging at temperature $450^{\circ} \mathrm{C}$. Experimental results of Sahu et al. [4] on impact properties changes of duplex stainless steel, Cortie and Pollak [40] on impact toughness of ferritic stainless steel and Vogt et al. [26] on a hardness increase of duplex stainless steels indirectly indicate that decomposition of the $\delta$ ferrite started after several tens of minutes of exposition on the temperature $475^{\circ} \mathrm{C}$. Similar results, indirectly indicating the relatively high rate of isothermal decomposition of the ferrite phase were presented by Soriano-Vargas et al. [35] on the hardening behavior of the $\mathrm{Fe}-\mathrm{Cr}$ alloy aged at $500^{\circ} \mathrm{C}$. Similarly, Hedström et al. [45] on the homogenized model alloys showed rapid decrease of impact toughness after their thermal exposition $500^{\circ} \mathrm{C} / 1 \mathrm{~h}$.

Kinetic dependences for decomposition of $\delta$-ferrite phase in stainless steels to $\alpha+\alpha^{\prime}$ phases by continual cooling are unavailable. However, it has been shown that the quenching rates after solution treatment at high temperatures above $1000^{\circ} \mathrm{C}$ may be important for the phase separation in the ferrite containing stainless steels [41, 42]. Recently, it has been shown that there is clustering of chromium atoms in the ferritic phase of ferritic and duplex corrosion resistant steels already after solution treatment and water quenching [48]. Virtual experiments of these authors show that the initial structure of the ferrite phase after solution treatment and quenching has a large effect on the subsequent phase separation during low-temperature aging.

From the size and position of weld beads in Fig. 2, it follows that the melting boundaries of the weld beads No. 2 and No. 3 are located in the very short distance from the analyzed zone of the weld metal. This means that during the creation of weld beads No. 2 and No. 3 analyzed spot of weld metal was affected by significantly higher temperatures, as remote weld beads No. 4 and No. 5 , since the weld beads material No. 2 and No. 3 acts during the creation of the last two weld beads as a thermal barrier.

From the presented literature data and localization, shape and size of the weld beads in the analyzed sample from the weld joint it can be supposed that the decomposition of $\delta$-ferrite phase in the analyzed region of the weld metal could start by the multipass-welding and cooling from the welding temperatures. We assume that structural changes on the nanoscale range in the ferritic phase documented in Figs. 8b and 9a probably started at temperatures below $500{ }^{\circ} \mathrm{C}$ during final stage formation of the weld joint, mainly during formation of the last weld beads No. 4 and No. 5. We can suppose that after welding of the primary pipeline of the NPP decomposition of the ferrite phase continued during the long-term service exposition at the temperatures approaching $300^{\circ} \mathrm{C}$ and resulted in decomposed nanostructures documented in Figs. 8b, 9a and $9 \mathrm{~b}$.

The low-temperature decomposition of ferrite phase in corrosion resistant steels can occur by either spinodal decomposition or by nucleation and growth. The transformation mechanism is affected by the chemical composition of the steel and temperature of the exposition. It was found that cold-deformation of duplex stainless steel can change the nature of the ferrite $\rightarrow\left(\alpha+\alpha^{\prime}\right)$-phase separation from nucleation and growth to spinodal decomposition [5]. Moreover, during low-temperature aging could be active a combination of decomposition mechanisms with both spinodal decomposition and nucleation and growth [30]. From the present work, it is not possible unambiguously to determine the mechanism of the ferrite phase decomposition. As already mentioned, the analyzed zone of weld metal was affected several times during the welding procedure, but the values of temperature and holding time at the elevated temperatures are unknown.

It is also well known that in weld metals after welding procedure remain the residual mechanical stresses. The size, orientation and distribution of mechanical stresses in analyzed weld metal are unknown, too. Several papers showed that mechanical stresses in corrosion-resistant alloys based on the binary system Fe-Cr alter the kinetics of low-temperature decomposition of $\delta$-ferrite and affect the morphology of decomposition products $[44,47,60]$. Based on these facts and our experimental findings can be clearly identified neither the mechanism of $\delta$-ferrite decomposition in analyzed weld metal nor the quality of generated nano-products of decomposition.

Considering the results of other studies $[5,27,30$, $35]$, it can be assumed that mottled image observed in the $\delta$-ferrite documented in Fig. $8 \mathrm{~b}$ is associated with the redistribution of $\mathrm{Fe}, \mathrm{Cr}$ and other alloying elements due to decomposition of the ferrite phase to $\alpha+\alpha^{\prime}$-phase. On the basis of the interconnected morphology of the nano-scaled phases documented in Fig. $8 \mathrm{~b}$ we assume that decomposition of the $\delta$-ferrite phase in this part of weld metal took place mainly via spinodal decomposition.

\section{Summary and conclusions}

In the paper, results of microscopic analyses of the 
sample taken from the weld joint in the primary circuit of the nuclear power plant WWER-440 are presented. Investigated sample of the weld metal was located in the upper part of the multi-pass weld joint exposed approximately $180,000 \mathrm{~h}$ at temperatures approaching $300^{\circ} \mathrm{C}$.

Analyzed weld metal exhibited mixed cellular/ dendritic microstructure of the austenite phase with a semi-continuous network of $\delta$-ferrite phase localized at the austenite boundaries. In the weld metal, globular non-metallic inclusions, as well as carbonitride particles of the MX type and particles of $\mathrm{M}_{23} \mathrm{C}_{6}$ carbides were identified. At the phase interfaces of $\delta$-ferrite/austenite, the presence of $\sigma$-phase particles was detected. The presence of $\sigma$-phase and $\mathrm{M}_{23} \mathrm{C}_{6}$ carbide particles in the top part of the weld metal can be explained as a consequence of the short-term high-temperature expositions of the analyzed region of the weld metal in the temperature range from about 900 to $600{ }^{\circ} \mathrm{C}$ during the multi-pass welding process.

HRTEM analysis of ferrite phase regions of the weld metal revealed in thin foils the presence of mottled contrast indicating the spinodal decomposition of the $\delta$-ferrite phase to Fe-rich $\alpha+\mathrm{Cr}$-rich $\alpha^{\prime}$-phases. It is supposed that the decomposition of $\delta$-ferrite phase could start by the final stage of the multi-pass welding process at temperatures around $475^{\circ} \mathrm{C}$ and then continued during the long-term operation exposition of the primary pipeline of the NPP at the temperatures approaching $300^{\circ} \mathrm{C}$.

It should be emphasized that presented results are characteristic only for very limited volume in the upper part of the weld. For a better understanding of the influence of thermal cycles during multi-pass welding and long-term exposition of the weld joint in the primary circuit of the NPP on the microstructure of the weld metal matrix and nanostructure of the $\delta$-ferrite phase, additional studies are required.

\section{Acknowledgements}

This article has been written thanks to the support of the research and development operation program project "Increase of the power safety in the Slovak Republic" (ITMS: 26220220077), co-financed from the European Regional Development Fund. The authors would like to thank Mr L. Kupča from the VUJE, Inc. Trnava for providing the sample from the weld joint after long-term aging in service conditions of the NPP WWER-440. The authors gratefully acknowledge the HRTEM analysis of Mrs Miroslawa Pawlyta from the Institute of Engineering Materials and Biomaterials, Silesian University of Technology, Gliwice, Poland on the Titan 80-300 microscope. The authors also acknowledge the discussion with Mrs Maria Behulova about thermal conditions of the weld joint formation. The authors are grateful to the reviewers for their inspiring remarks and suggestions.

\section{References}

[1] IAEA-TECDOC-1361, Assessment and Management of Major Nuclear Power Plant Ageing Components Important to Safety. Primary Piping in PWRs. Vienna, IAEA 2003.

[2] Lippold, J. C., Kotecki, D. J.: Welding Metallurgy and Weldability of Stainless Steels. Hoboken, Wiley-Interscience 2005.

[3] Bermejo, M. A.V.: Welding Journal, 91, 2012, p. 113.

[4] Sahu, J. K., Krupp, U., Ghosh, R. N., Christ, H.-J.: Materials Science and Engineering A, 508, 2009, p. 1. doi:10.1016/j.msea.2009.01.039

[5] Hätterstrand, M., Larsson, P., Guocai Chai, Nilsson, J.-O., Odqvist, J.: Materials Science and Engineering A, 499, 2009, p. 489. doi:10.1016/i.msea.2008.09.021

[6] Nichol, T. J., Datta, A., Aggen, G.: Metallurgical Transactions A, 11, 1980, p. 573. doi:10.1007/BF02670694

[7] Joly, P., Cozar, R., Pincau, A.: Scripta Metallurgica et Materialia, 24, 1990, p. 2235. doi:10.1016/0956-716X(90)90071-N

[8] Chopra, O. K.: Studies of Aged Cast Stainless Steel from the Shippingport Reactor. Illinois, Argonne National Laboratory 1991.

[9] Michaud, W. F., Toben, P. T., Soppet, W. K., Chopra, O. K.: Tensile-Property Characterization of Thermally Aged Cast Stainless Steels. NUREG/CR-6142. ANL-93/35. Illinois, Argonne National Laboratory 1994.

[10] Hyde, J. M., Miller, M. K., Cerezo, A., Smith, G. D. W.: Applied Surface Science, 87/88, 1995, p. 311. doi:10.1016/0169-4332(94)00498-6

[11] Miller, M. K., Hyde, J. M., Cerezo, A., Smith, G. D. W.: Applied Surface Science, 87/88, 1995, p. 323. doi:10.1016/0169-4332(95)00497-1

[12] Miller, M. K., Hyde, J. M., Hetherington, M. G., Cerezo, A., Smith, G. D. W., Elliot, C. M.: Acta Metallurgica et Materialia, 43, 1995, p. 3385. doi:10.1016/0956-7151(95)00040-3

[13] Miller, M. K., Hyde, J. M., Hetherington, M. G., Cerezo, A., Smith, G. D. W., Elliot, C. M.: Acta Metallurgica et Materialia, 43, 1995, p. 3403. doi:10.1016/0956-7151(95)00041-S

[14] Miller, M. K., Hyde, J. M., Hetherington, M. G., Cerezo, A., Smith, G. D. W., Elliot, C. M.: Acta Metallurgica et Materialia, 43, 1995, p. 3415. doi:10.1016/0956-7151(95)00042-T

[15] Yi, Y. S., Shoji, T.: Journal of Nuclear Materials, 240, 1996, p. 62. doi:10.1016/S0022-3115(96)00459-X

[16] Nyström, M., Karlsson, B.: Materials Science and Engineering A, 215, 1996, p. 26. doi:10.1016/0921-5093(96)10251-3

[17] Llanes, L., Mateo, A., Violan, P., Méndez, J., Anglada, M.: Materials Science and Engineering A, 234-236, 1997, p. 850. doi:10.1016/S0921-5093(97)00359-6

[18] Mateo, A., Llanes, L., Anglada, M., Redjaimia, A., Metauer, G.: Journal of Materials Science, 32, 1997, p. 4533. doi:10.1023/A:1018669217124

[19] Maeda, N., Goto, T., Kamimura, T., Naito, T., Kumano, S., Nakao, Y.: International Journal of Pressure Vessels \& Piping, 71, 1997, p. 7. doi:10.1016/S0308-0161(96)00015-4

[20] Kawaguchi, S., Sakamoto, N., Takano, G., Matsuda, F., Kikuchi, Y., Mráz, L.: Nuclear Engineering and 
Design, 174, 1997, p. 273.

doi:10.1016/S0029-5493(97)00126-X

[21] Danoix, F., Auger, P.: Materials Characterization, 44, 2000, p. 177. doi:10.1016/S1044-5803(99)00048-0

[22] Sunki Kim, Yongsoo Kim: Journal of the Korean Nuclear Society, 30, 1998, p. 609.

[23] Chan-Jin Park, Hyuk-Sang Kwon, Lohrengel, M. M.: Materials Science and Engineering A, 372, 2004, p. 180. doi:10.1016/i.msea.2003.12.013

[24] Iacoviello, F., Casari, F., Gialanella, S.: Corrosion Science, 47, 2005, p. 909. doi:10.1016/i.corsci.2004.06.012

[25] Tavares, S. S. M., De Noronha, R. F., Da Silva, M. R., Neto, J. M., Pairis, S.: Materials Research, 4, 2001, p. 237. doi:10.1590/S1516-14392001000400003

[26] Vogt, J.-B., Massol, K., Foct, J.: International Journal of Fatigue, 24, 2002, p. 627. doi:10.1016/S0142-1123(01)00187-6

[27] Weng, K. L., Chen, H. R., Yang, J. R.: Materials Science and Engineering A, 379, 2004, p. 119. doi:10.1016/j.msea.2003.12.051

[28] Yamada, T., Okano, S., Kuwano, H.: Journal of Nuclear Materials, 350, 2006, p. 47. doi:10.1016/i.jnucmat.2005.11.008

[29] Vojvodič-Tuma, J., Suštaršič, B., Vodopivec, F.: Nuclear Engineering and Design, 238, 2008, p. 1511. doi:10.1016/j.nucengdes.2008.01.014

[30] Hedström, P., Baghsherkhi, S., Liu, P., Odqvist, J.: Materials Science and Engineering A, 534, 2012, p. 552. doi:10.1016/j.msea.2011.12.007

[31] Cicero, S., Setién, J., Gorrochategui, I.: Nuclear Engineering and Design, 239, 2009, p. 16. doi:10.1016/j.nucengdes.2008.09.009

[32] Wang, X., Li, S., Li, S., Wang, Y., Xue, F., Shu, G.: MRS Proceedings, 1215, 2009, 1215-V18-07. doi:10.1557/PROC-1215-V18-07

[33] Wang, Z.-X., Xue, F., Jiang, J.-W., Ti, W.-X., Yu, W.-W.: Engineering Failure Analysis, 18, 2011, p. 403. doi:10.1016/j.engfailanal.2010.09.022

[34] Armas, A. F., Hereňú, S., Alvarez-Armas, I., Degallaix, S., Condó, A., Lovey, F.: Materials Science and Engineering, A491, 2008, p. 434. doi:10.1016/j.msea.2008.02.028

[35] Soriano-Vargas, O., Avila-Davila, E. O., Lopez-Hirata, V. M., Cayetano-Castro, N., Gonzales-Velasquez, J. L.: Materials Science and Engineering A, 527, 2010, p. 2910. doi:10.1016/j.msea.2010.01.020

[36] Akita, M., Kakiuchi, T., Uematsu, Y.: Procedia Engineering, 10, 2011, p. 100. doi:10.1016/j.proeng.2011.04.019

[37] Pareige, C., Novy, S., Saillet, S., Pareige, P.: Journal of Nuclear Materials, 411, 2011, p. 90. doi:10.1016/j.jnucmat.2011.01.036

[38] Hamaoka, T., Nomoto, A., Nishida, K., Dohi, K., Soneda, N.: Philosophical Magazine, 92, 2012, p. 4354. doi:10.1080/14786435.2012.707340

[39] Fujii, K., Fukuya, K.: Journal of Nuclear Materials, 440, 2013, p. 612. doi:10.1016/i.jnucmat.2013.04.072

[40] Cortie, M. B., Pollak, H.: Materials Science and Engineering A, 199, 1995, p. 153. doi:10.1016/0921-5093(94)09731-3

[41] Hedin, M., Massoud, J., Danoix, F.: Journal de Physique IV, 6, 1996, p. 235. doi:10.1051/ip4:1996538

[42] Lemoine, C., Fnidiki, A., Teillet, J., Hédin, M.,
Danoix, F.: Scripta Materialia, 39, 1998, p. 61. doi:10.1016/S1359-6462(98)00133-X

[43] Soriano-Vargas, O., Avila-Davila, E. O., Lopez-Hirata, V. M., Dorantes-Rozales, H. J., Gonzalez-Velazquez, J. L.: Materials Transactions, 50, 2009, p. 1753. doi:10.2320/matertrans.M2009029

[44] Li, Y.-S., Li, S.-X., Zhang, T.-Y.: Journal of Nuclear Materials, 395, 2009, p. 120.

doi:10.1016/i.jnucmat.2009.10.042

[45] Hedström, P., Fei, H., Jing, Z., Wessman, S., Thuvander, M., Odqvist, J.: Materials Science and Engineering A, 574, 2013, p. 123. doi:10.1016/j.msea.2013.03.016

[46] Jing, Z., Odqvist, J., Thuvandr, M., Hedström, P.: Microscopy and Microanalysis, 19, 2013, p. 665. doi:10.1017/S1431927613000470

[47] Danoix, F., Lacaze, J., Gibert, A., Mangelinck, D., Hoummada, K., Andrieu, E.: Ultramicroscopy, 132, 2013, p. 193. doi:10.1016/j.ultramic.2012.12.004

[48] Jing, Z., Odqvist, J., Höglund, L., Thuvander M., Barkar, T., Hedström, P.: Scripta Materialia, 75, 2014, p. 62. doi:10.1016/j.scriptamat.2013.11.020

[49] Tucker, J. D., Miller, M. K., Young, G. A.: Acta Materialia, 87, 2015, p. 15. doi:10.1016/j.actamat.2014.12.012

[50] Vitek, J. M., David, S. A., Alexander, D. J., Keiser, J. R., Nanstad, R. K.: Acta Metallurgica et Materialia, 39, 1991, p. 503. doi:10.1016/0956-7151(91)90118-K

[51] Nilsson, J. O., Liu, P.: Materials Science and Technology, 7, 1991, p. 853. doi:10.1179/mst.1991.7.9.853

[52] Gavenda, D. J., Michaud, W. F., Galvin, T. M., Burke, W. F., and Chopra, O. K.: Effects of Thermal Aging on Fracture Toughness and Charpy-Impact Strength of Stainless Steel Pipe Welds. Illinois, Argonne National Laboratory 1996.

[53] Mamaeva, E., Bakirov, M., Rafalovich, I., Kharina, I., Fedorova, O.: In: Proceedings of the 26th ESReDA. Seminar on Lifetime Management of Industrial Systems. Eds.: Simola, K., Cojazzi, G. G. M. Ispra, JRC 2006, p. 1.

[54] Shafy, M.: Egyptian Journal of Solids, 28, 2005, p. 325.

[55] Shafy, M.: Egyptian Journal of Solids, 29, 2006, p. 151.

[56] Lucas, T.: The Effect of Thermal Aging and Boiling Water Reactor Environment on Type 316 L Stainless Steel Welds. [PhD Thesis]. Cambridge, Massachusetts Institute of Technology 2011.

[57] Chandra, K., Vivekanand Kain, Vikas Bhutani, Raja, V. S., Tewari, R., Dey, G. K., Chakravarrty, J. K.: Materials Science and Engineering A, 534, 2012, 163. doi:10.1016/i.msea.2011.11.055

[58] Chandra, K., Vivekanand Kain, Raja, V. S., Tewari, R., Dey, G. K.: Corrosion Science, 54, 2012, p. 278. doi:10.1016/j.corsci.2011.09.031

[59] Shariq, A., Hättestrand, M., Nillson, J.-O., Gregori, A.: Journal of Nanoscience and Nanotechnology, 9, 2009, p. 3657. doi:10.1166/jnn.2009.NS47

[60] Zhou, J., Odqvist, J., Thuvander, M., Hertzman, S., Hedström, P.: Acta Materialia, 60, 2012, p. 5818. doi:10.1016/j.actamat.2012.07.022

[61] Li, J., Wu, T., Riquier, Y.: Materials Science and Engineering A, 174, 1994, p. 149. doi:10.1016/0921-5093(94)91083-9

[62] Lee, K. M., Cho, H. S., Choi, D. C.: Journal of Alloys 
and Compounds, 285, 1999, p. 156.

doi:10.1016/S0925-8388(99)00014-6

[63] Chen, T. H., Yang, J. R.: Materials Science and Engineering A, 338, 2002, p. 166. doi:10.1016/S0921-5093(02)00065-5

[64] Sahlaoui, H., Makhlouf, K., Sidhom, H., Philibert, J.: Materials Science and Engineering A, 372, 2004, p. 98. doi:10.1016/j.msea.2003.12.017

[65] Huang, C.-S., Shih, C.-C.: Materials Science and Engineering A, 402, 2005, p. 66. doi:10.1016/i.msea.2005.03.111

[66] Michalska, J., Sozańska, M.: Materials Characterization, 56, 2006, p. 355.

doi:10.1016/i.matchar.2005.11.003

[67] Sieurin, H., Sandström, R.: Materials Science and Engineering A, 444, 2007, p. 271. doi:10.1016/j.msea.2006.08.107

[68] Sato, Y. S., Kokawa, H.: Scripta Materialia, 40, 1999, p. 659. doi:10.1016/S1359-6462(98)00483-7

[69] De Mélo, E. B., Magnabosco, R., de Moura Neto, C.: Materials Research, 16, 2013, p. 1336. doi:10.1590/S1516-14392013005000125

[70] Biezma, M. V., Berlanga, C., Argandona, G.: Materials Research, 16, 2013, p. 965. doi:10.1590/S1516-14392013005000085

[71] Parvathavarthini, N., Dayal, R. K., Khatak, H. S., Shankar, V., Shanmugan, V.: Journal of Nuclear Materials, 355,2006 , p. 68 . doi:10.1016/j.jnucmat.2006.04.006
[72] Liu, F., Hwang, Y. H., Nam, S. W.: Materials Science and Engineering A, 483-484, 2008, p. 418. doi:10.1016/j.msea.2006.08.141

[73] Chen, T. H., Yang, J. R.: Materials Science and Engineering A, 311, 2001, p. 28. doi:10.1016/S0921-5093(01)00911-X

[74] Cieslak, M. J., Ritter, A. M., Savage, W. F.: Welding Research Supplement, 4, 1984, p. 133-s.

[75] Karlsson, L., Ryen, L., Pak, S.: Welding Research Supplement, 1, 1995, p. 28-s.

[76] Heino, S., Knutson-Wedel, F. M., Karlsson, B.: Materials Science and Technology, 15, 1999, p. 101. doi:10.1179/026708399773003376

[77] Perricone, M. J., Anderson, T. D., Robino, C. V., Dupont, J. N., Michael, J. R.: Metallurgical and Materials Transactions A, 38, 2007, p. 1976. doi:10.1007/s11661-007-9158-x

[78] Chih-Chun Hsieh, Weite Wu: Journal of Alloys and Compounds, 506, 2010, p. 820. doi:10.1016/i.jallcom.2010.07.084

[79] Ling, C.-M., Tsai, H.-L., Cheng, C.-D., Cheng Yang: Engineering Failure Analysis, 21, 2012, p. 9. doi:10.1016/i.engfailanal.2011.11.014

[80] Kupča, L.: Personal information. Trnava,VUJE, Inc.

[81] Kaneko, K., Fukunaga, T., Yamada, K., Nakada, N., Kikuchi, M., Saghi, Z. Barnard, J. S., Midgley, P. A.: Scripta Materialia, 65, 2011, p. 509. $\underline{\text { doi:10.1016/i.scriptamat.2011.06.010 }}$ 